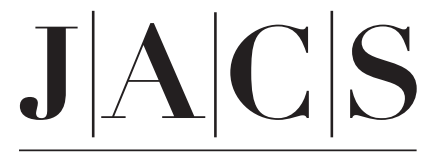

A R T I C L E S

Published on Web 07/27/2007

\title{
Measuring Location, Size, Distribution, and Loading of NiO Crystallites in Individual SBA-15 Pores by Electron Tomography
}

\author{
Heiner Friedrich, ${ }^{*}, \dagger$ Jelle R. A. Sietsma, ${ }^{\dagger}$ Petra E. de Jongh, ${ }^{\dagger}$ Arie J. Verkleij, ${ }^{\ddagger}$ and \\ Krijn P. de Jong ${ }^{*, \dagger}$ \\ Contribution from Inorganic Chemistry and Catalysis, Utrecht University, \\ Sorbonnelaan 16, 3584 CA Utrecht, The Netherlands, and Molecular Cell Biology, \\ Utrecht University, Padualaan 8, 3584 CA Utrecht, The Netherlands
}

Received April 25, 2007; E-mail: h.friedrich@uu.nl; k.p.dejong@uu.nl

\begin{abstract}
By the combination of electron tomography with image segmentation, the properties of $299 \mathrm{NiO}$ crystallites contained in 6 SBA-15 pores were studied. A statistical analysis of the particle size showed that crystallites between 2 and $6 \mathrm{~nm}$ were present with a distribution maximum at 3 and $4 \mathrm{~nm}$, for the number-weighted and volume-weighted curves, respectively. Interparticle distances between nearest neighbors were $1-3 \mathrm{~nm}$ with very few isolated crystallites. In the examined pores, a local loading twice the applied average of $24 \mathrm{wt} \% \mathrm{NiO}$ was found. This suggests that a very high local loading combined with a high dispersion is achievable.
\end{abstract}

\section{Introduction}

The intermediate size regime of nanostructured materials, where the collective behavior of bulk materials emerges from the discrete nature of molecular properties, provides the opportunity to observe unusual optical, ${ }^{1}$ magnetic, ${ }^{2}$ and catalytic ${ }^{3}$ behavior. One important factor for the design and production of such novel materials, in general, and more efficient catalysts, in particular, is the development of new characterization procedures. In heterogeneous catalysis, size, structure, location, distribution, and accessibility of the active particles within the support determine the selectivity and activity of the catalyst. Since commercial catalysts are highly complex, fundamental studies are advantageously carried out on well-defined model systems. In this respect ordered mesoporous materials (OMM) have attracted much attention as model supports since $1992 .{ }^{4,5}$ This special interest can be attributed to their tunable but welldefined pore geometry, bridging the gap between ordered microporous zeolites and disordered meso- and macroporous oxides. One of the most widely studied ordered mesoporous silica is SBA-15, exposing a two-dimensional hexagonal symmetry of cylindrical pores. ${ }^{6}$ Its thermostability and the extensive

$\dagger$ Inorganic Chemistry and Catalysis.

Molecular Cell Biology.

(1) Murray, C. B.; Norris, D. J.; Bawendi, M. G. J. Am. Chem. Soc. 1993, $115,8706$.

(2) Bala, T.; Sankar, C. R.; Baidakova, M.; Osipov, V.; Enoki, T.; Joy, P. A.; Prasad, P. L. V.; Sastry, M. Langmuir 2005, 21, 10638.

(3) Bezemer, G. L.; Bitter, J. H.; Kuipers, H. P. C. E.; Oosterbeek, H.; Holewijn, J. H.; Xu, X.; Kaptein, F.; van Dillen, A. J.; de Jong, K. P. J. Am Chem. Soc. 2006, 128, 3956

(4) Kresge, C. T.; Leonowicz, M. E.; Roth, W. J.; Vartuli, J. C.; Beck, J. S. Nature 1992, 359, 710.

(5) Beck, J. S.; Vartuli, J. C.; Roth, W. J.; Leonowicz, M. E.; Kresge, C. T.; Schmitt, K. D.; Chu, C. T.-W.; Olson, D. H.; Sheppard, E. W.; McCullen, S. B.; Higgins, J. B.; Schlenkert, J. L. J. Am. Chem. Soc. 1992, 114, 10834

(6) Zhao, D.; Feng, J.; Huo, Q.; Melosh, N.; Fredrickson, G. H.; Chmelka, B. F.; Stucky, G. D. Science 1998, 279, 548.

10.1021/ja0728876 CCC: $\$ 37.00$ ๑ 2007 American Chemical Society prior research ${ }^{7-19}$ make catalysts prepared from SBA-15 ideal model systems. For this study, a highly dispersed NiO/SBA-15 intermediate was chosen, since nickel is used as active component in many industrially relevant processes. ${ }^{20-23}$

Structural characterization of OMM-based catalysts to study the influence of various preparation treatments is mostly carried out by bulk techniques, such as, $\mathrm{N}_{2}$-physisorption ${ }^{10-19}$ or X-ray diffraction $^{12-19}$ (XRD). From these measurements structural parameters, like pore diameter, pore wall thickness, particle size, and accessibility of the active phase, are derived. One major

(7) Janssen, A. H.; Van Der Voort, P.; Koster, A. J.; de Jong, K. P. Chem. Commun. 2002, 1632

(8) Janssen, A. H.; Yang, C.-M.; Wang, Y.; Schüth, F.; Koster, A. J.; de Jong, K. P. J. Phys. Chem. B 2003, 107, 10552

(9) Ziese, U.; de Jong, K. P.; Koster, A. J. Appl. Catal., A 2004, 260, 71

(10) Ravikovitch, P. I.; Neimark, A. V. J. Phys. Chem. B 2001, 105, 6817

(11) Van Der Voort, P.; Ravikovitch, P. I.; de Jong, K. P.; Neimark, A. V.; Janssen, A. H.; Benjelloun, M.; Van Bavel, E.; Cool, P.; Weckhuysen, B M.; Vasant, E. F. Chem. Commun. 2002, 1010.

(12) Khodakov, A. Y.; Zholobenko, V. L.; Bechara, R.; Durand, D. Microporous Mesoporous Mater. 2005, 79, 29.

(13) Esparza, J. M.; Ojeda, M. L.; Campero, A.; Domínguez, A.; Kornhauser, I.; Rojas, F.; Vidales, A. M.; López, R. H.; Zgrablich, G. Colloids Surf., A 2004, 241,35 .

(14) Sietsma, J. R. A.; Van Dillen, A. J.; de Jongh, P. E.; de Jong, K. P. Stud. Surf. Sci. Catal. 2006, 162, 95.

(15) Kantorovich, D.; Haviv, L.; Vradman, L.; Landau, M. V. Stud. Surf. Sci. Catal. 2005, 156, 147.

(16) Vradman, L.; Landau, M. V.; Kantorovich, D.; Koltypin, Y.; Gedanken, A. Microporous Mesoporous Mater. 2005, 79, 307.

(17) Cho, Y. S.; Park, J. C.; Lee, B.; Kim, Y.; Yi, J. Catal. Lett. 2002, 81, 89

(18) Li, X.-K.; Ji, W.-J.; Zhao, J.; Wang, S.-J.; Au, C.-T. J. Catal. 2005, 236, 181

(19) Park, Y.; Kang, T.; Kim, P.; Yi, J. J. Colloid Interface Sci. 2006, 295, 464.

(20) Satterfield, C. N. Heterogeneous Catalysis in Practice; McGraw-Hill: New York, 1980

(21) Bond, G. C. Heterogeneous Catalysis; Oxford University Press: Oxford, U.K., 1988.

(22) Augustine, R. L. Heterogeneous Catalysis for the Synthetic Chemist; Marcel Dekker, Inc: New York, 1996.

(23) van der Lee, M. K.; van Dillen, A. J.; Bitter, J. H.; de Jong, K. P. J. Am. Chem. Soc. 2005, 127, 13573. 
drawback of bulk techniques is that no direct information on the actual location and distribution of the active particles within the support is obtained. If additional, spatially resolved information is required, transmission electron microscopy (TEM) ${ }^{14-19,24-27}$ and scanning electron microscopy (SEM) $)^{25-29}$ are applied. Although TEM is a very powerful technique, the resulting images are in first approximation a two-dimensional (2D) projection of a three-dimensional (3D) structure. ${ }^{30}$ This implies that for complex 3D objects, like the examined NiO/SBA-15, the actual 3D location and distribution of the $\mathrm{NiO}$ phase cannot be unambiguously determined from single TEM images.

Complex 3D structures can be imaged using electron tomography (ET), sometimes referred to as 3D-TEM, which combines multiple TEM images from different directions. ${ }^{7-9,24-27,31-35}$ First applications of ET to heterogeneous catalysts focused on the qualitative description of the observed nanoscale structures. ${ }^{7-9}$ More recent applications involve a posteriori image segmentation to quantify catalyst properties, like, porosity, ${ }^{33}$ localization of the active phase, ${ }^{34}$ and loading of active components. ${ }^{35}$ As for any data derived from electron microscopy, care has to be taken that the imaged structures are representative for the bulk; thus, bulk characterization is mandatory to provide a basis to evaluate the relevance of nanoscale observations. In this study, ET in combination with posteriori image segmentation is applied to measure the $3 \mathrm{D}$ location and size of single $\mathrm{NiO}$ crystallites in individual SBA-15 pores. On the basis of the segmentation results, the $\mathrm{NiO}$ particle size distribution, 3D nearest neighbor distances, and a loading model of individual SBA-15 pores are derived. Obtained results are verified and discussed in context of the bulk characterization. To our knowledge, this is the first application of ET to quantify the particle size distribution, 3D nearest neighbor distances, and the local loading in individual pores of the support material.

\section{Materials and Methods}

Preparation of NiO/SBA-15. SBA-15 (pore volume $0.73 \mathrm{~cm}^{3} \cdot \mathrm{g}^{-1}$ ) was synthesized according to a procedure described by Zhao. ${ }^{6}$ Deposition of the $\mathrm{NiO}$ precursor was carried out by incipient wetness impregnation of SBA-15 using a $4.2 \mathrm{M}$ aqueous $\mathrm{Ni}\left(\mathrm{NO}_{3}\right)_{2}$ solution $(\mathrm{Ni}-$ $\left(\mathrm{NO}_{3}\right)_{2} \cdot 6 \mathrm{H}_{2} \mathrm{O}$ (Acros) in demineralized water) followed by drying at $120^{\circ} \mathrm{C}$ for $12 \mathrm{~h}$. Conversion of the dried precursor was done by heating the sample at $1{ }^{\circ} \mathrm{C} \cdot \mathrm{min}^{-1}$ to $450{ }^{\circ} \mathrm{C}$ in a flow of 1 vol \% NO in He. The sample was kept at $450{ }^{\circ} \mathrm{C}$ for $4 \mathrm{~h}$. Following this procedure, highly dispersed NiO/SBA-15 at a loading of $24 \mathrm{wt} \% \mathrm{NiO}$ was obtained. ${ }^{36}$

(24) Meurig Thomas, J.; Midgley, P. A. Chem. Commun. 2004, 1253.

(25) Datye, A. K. J. Catal. 2003, 216, 144

(26) Gai, P. L.; Boyes E. D. Electron microscopy in heterogeneous catalysis; Institute of Physics Publishing: Bristol, U.K., 2003.

(27) Anderson, M. W.; Ohsuna, T.; Sakamoto, Y.; Liu, Z.; Carlsson, A.; Terasaki, O. Chem. Commun. 2004, 907.

(28) Smith, D. J.; Yao, M. H.; Allard, L. F.; Datye, A. K. Catal. Lett. 1995, 31 , 57.

(29) Bore, M. T.; Pham, H. N.; Switzer, E. E.; Ward, T. L.; Fukuoka, A.; Datye, A. K. J. Phys. Chem. B 2005, 109, 2873.

(30) Hawkes, P. W. The Electron Microscope as a Structure Projector. In Electron Tomography: Three-Dimensional Imaging with the Transmission Electron Microscope; Frank, J., Ed.; Plenum Press: New York, 1992.

(31) Weyland, M.; Midgley, P. A.; Meurig Thomas, J. J. Phys. Chem. B 2001 , $105,7882$.

(32) de Jong, K. P.; Koster, A. J. ChemPhysChem 2002, 3, 776.

(33) Ziese, U.; Gommes, C. J.; Blacher, S.; Janssen, A. J.; Koster, A. J.; de Jong, K. P. Stud. Surf. Sci. Catal. 2005, 158, 633.

(34) Gommes, C. J.; de Jong, K. P.; Pirard, J. P.; Blacher, S. Langmuir 2005 21, 12378.

(35) Midgley, P. A.; Meurig Thomas, J.; Laffont, L.; Weyland, M.; Raja, R.; Johnson, B. F. G.; Khimyak, T. J. Phys Chem. B 2004, 108, 4590.

(36) Sietsma, J. R. A.; van Dillen, A. J.; de Jongh, P. E.; de Jong, K. P. Angew. Chem., Int. Ed. 2007, 46, 4547.
XRD and $\mathbf{N}_{2}$-Physisorption. Powder XRD measurements were performed with a Bruker AXS D8 Advance diffractometer using Co $\mathrm{K} \alpha_{1,2}$ radiation with a wavelength of $0.179 \mathrm{~nm}$. Small-angle XRD patterns of the SBA-15 material were recorded from $0.5-5^{\circ}(2 \theta)$ at an angular increment of $0.0086^{\circ}$. The diffraction pattern was corrected for the $\mathrm{K \alpha}_{2}$ component prior to further processing. To provide reproducible results and minimize effects of XRD sample preparation, the average over eight individual small angle XRD patterns was taken. XRD measurements of the NiO/SBA- 15 were obtained from 40 to $100^{\circ}$ $(2 \theta)$ at an angular increment of $0.0086^{\circ}$. The $\mathrm{NiO}$ crystallite size was calculated from the fwhm of the broadened diffraction peaks using the Scherrer equation.

$\mathrm{N}_{2}$-physisorption measurements were performed at $-196{ }^{\circ} \mathrm{C}(\mathrm{Mi}-$ cromeritics, TriStar 3000 V6.01 A) on the SBA-15 and the NiO/SBA15 intermediate. From the adsorption isotherms, the pore volume and pore size distribution were deduced using NL-DFT theory ${ }^{37-39}$ implemented in the DataMaster 4.01 software (Micromeritics).

Electron Tomography (ET). TEM tomography grids were prepared by applying $10 \mathrm{~nm}$ sized colloidal gold particles (Aurion, PAG conjugated) from aqueous suspension to a Quantifoil R2/1 carbon film supported on a parallel bar $\mathrm{Cu}$ TEM grid. After drying in air, a small amount of the NiO/SBA-15 powder was deposited directly onto the grid. Excess catalyst was shook-off before inserting the TEM grid into a Fischione, model 2020, advanced tomography holder. ET was performed in bright-field TEM mode using a Tecnai 20 electron microscope (FEI) operating at $200 \mathrm{kV}$ acceleration voltage, equipped with a $\mathrm{LaB}_{6}$ electron source and a TWIN objective lens. A series of TEM images (tilt-series) were acquired by rotating the specimen inside the microscope over a tilt range of at least +70 to $-70^{\circ}$ at increments of $1^{\circ}$. Images were recorded at each tilt step on a 2048 pixel $\times 2048$ pixel TVIPS CCD camera using Xplore3D software (FEI). Diffraction effects caused by a combination of the microscope aberrations and strongly excited high-order beams, resulting in nonsymmetric white halos around crystalline material, were excluded by using an objective aperture. The defocus was set between -130 and $-200 \mathrm{~nm}$ depending on the thickness of the examined SBA-15 particle to keep the entire object in underfocus. The nominal magnification was $29000 \times$, which corresponds to a pixel size of $0.27 \mathrm{~nm}$. Images of the tilt-series were aligned with respect to a common origin and rotation axis using the 10 $\mathrm{nm}$ gold particles as fiducial markers. Finally the aligned tilt-series was binned to $0.54 \mathrm{~nm}$ pixel size prior to reconstruction of the threedimensional volume. Alignment and reconstruction by filtered backprojection was performed in IMOD. ${ }^{40}$ Preliminary results using the sequential iterative reconstruction technique (SIRT) showed good contrast in the reconstruction but did not improve the segmentation described in the next paragraph.

Assessment of the $\mathrm{NiO}$ phase within the SBA-15 mesopores, a process called segmentation, was carried out in Amira 3.1 (TGS-Visual Concepts/Mercury Computer Systems, Inc.). Segmentation involved in a first step the manual tracing of the $\mathrm{NiO}$ crystallite contours throughout the volume of the examined mesopores. Since the NiO crystallites are three-dimensional, three perpendicular cutting planes were used to identify connected regions with dark contrast. As practical limit for the smallest detectable particle, a connected region of at least $3 \times 3 \times$ 2 pixels $\left(\sim 3 \mathrm{~nm}^{3}\right)$ had to be present. This practical limit exceeds the rule-of-thumb for the theoretically predicted resolution which equals three times the thickness of the sample divided by the number of images. However, the practical achievable resolution has been reported to be considerably better than the calculated value. ${ }^{9,31}$ In the last segmentation step, the volume and the center-of-mass of each $\mathrm{NiO}$ crystallite were calculated.

(37) Tarazona, P. Phys. Rev. A 1985, 31, 2672

(38) Tarazona, P. Phys. Rev. A 1985, 32, 3148.

(39) Tarazona, P.; Marini Bettolo Marconi, U.; Evans, R. Mol. Phys. 1987, 60 , 573.

(40) Kremer, J. R.; Mastronarde, D. N.; McIntosh, J. R. J. Struct. Biol. 1996, 116,71 . 
(a)

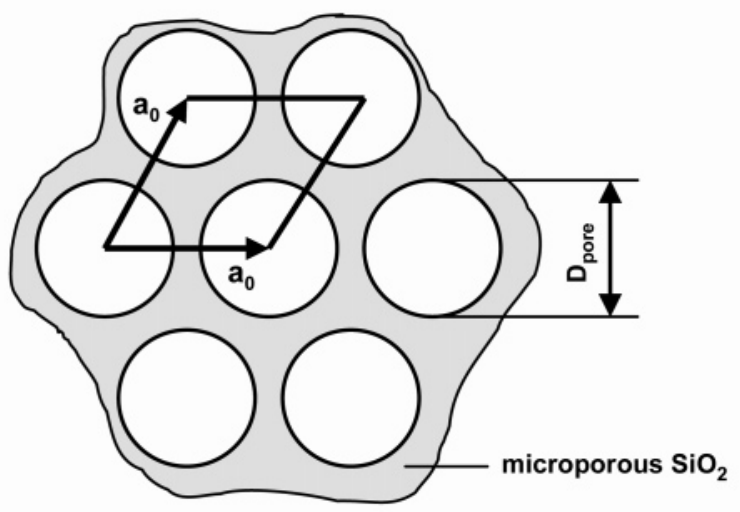

(b)

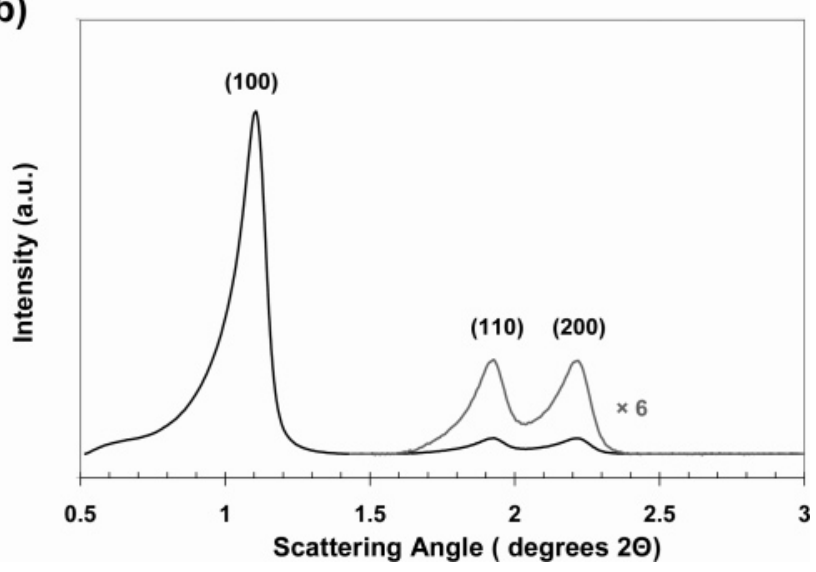

Figure 1. Geometrical model of the hexagonal mesopore ordering in SBA15 (a) and low-angle XRD pattern (b).

\section{Results and Discussion}

Bulk Characterization. A schematic model of the SBA-15 support is shown in Figure 1a. The straight cylindrical pores are viewed along the pore direction and the $2 \mathrm{D}$ hexagonal symmetry $(p 6 \mathrm{~mm})$ of the pore ordering is apparent. The smallangle XRD pattern of the SBA-15 (Figure 1b) shows distinct peaks that are associated with the hexagonal symmetry. ${ }^{6}$ From the position of the first three peaks, the unit cell size $\left(a_{0}\right)$ was calculated to $10.5 \pm 0.2 \mathrm{~nm}$.

The corresponding SBA-15 adsorption and desorption isotherms with their typical hysteresis loop are displayed in Figure 2a. Analysis by NL-DFT calculations ${ }^{37-39}$ gave a porosity of $0.73 \mathrm{~cm}^{3} \cdot \mathrm{g}^{-1}$ and a very narrow pore size distribution with a maximum at $9 \mathrm{~nm}$ (Figure 2b). These results confirm a uniform SBA-15 support with $1-2 \mathrm{~nm}$ thick pore walls.

Upon addition of the $\mathrm{NiO}$ phase to the SBA-15 support by impregnation, drying, and calcination, the accessible pore volume decreased (Figure 2a). The desorption branch of the isotherm did not indicate a significant mesopore blocking. ${ }^{8,11}$ NL-DFT analysis yielded a porosity of $0.54 \mathrm{~cm}^{3} \cdot \mathrm{g}^{-1}$ and a pore size distribution similar to the one observed for the blank SBA15 with the maximum again at $9 \mathrm{~nm}$ (Figure 2b). The XRD pattern of NiO/SBA-15 (Figure 3) displays three distinct peaks associated with the $\mathrm{NiO}$ crystal structure. The width of the diffraction peaks confirmed that only nanometer-sized $\mathrm{NiO}$ crystallites were created upon calcination of the precursor. All three peaks had a fwhm that led via the Scherrer equation to a $\mathrm{NiO}$ crystallite size of $4 \mathrm{~nm}$. The formation of small $\mathrm{NiO}$
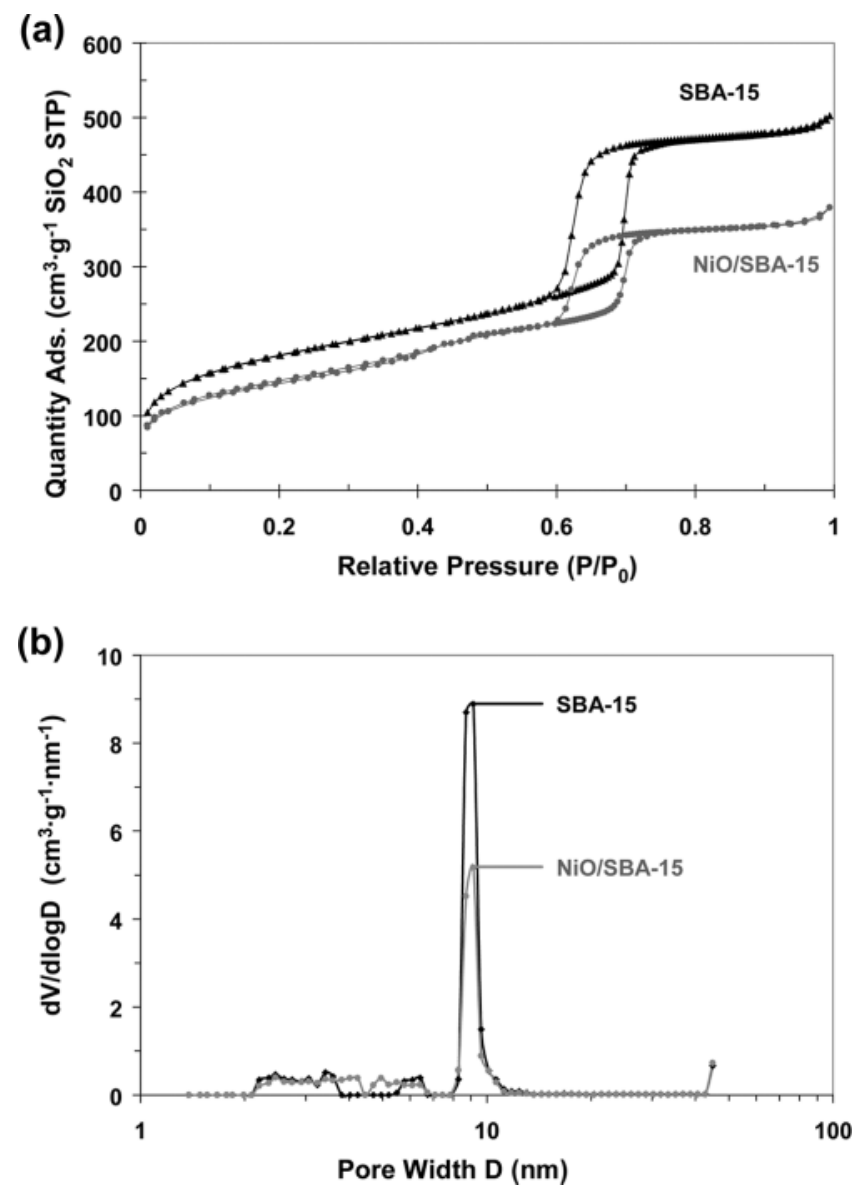

Figure 2. $\mathrm{N}_{2}$ adsorption and desorption isotherms of SBA-15 and $\mathrm{NiO} /$ SBA-15 (a) and pore size distributions derived by NL-DFT (b).

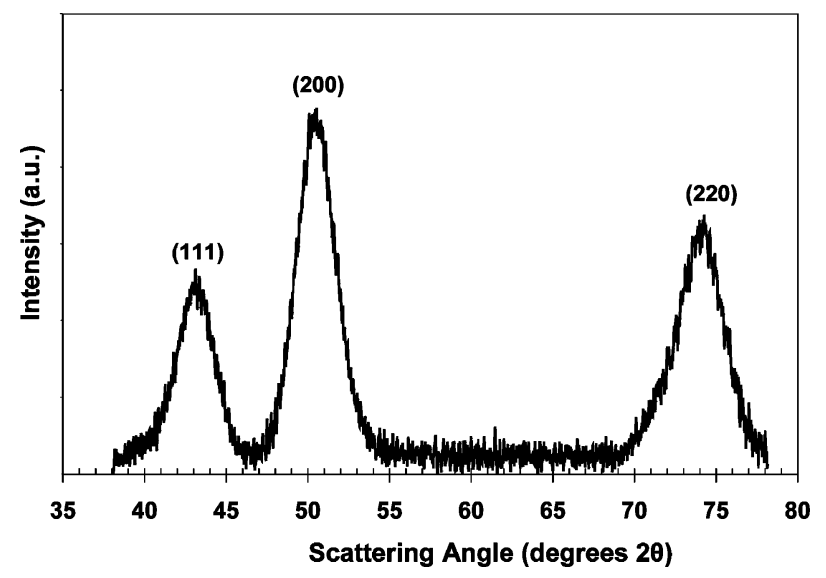

Figure 3. $\mathrm{XRD}$ pattern of the $\mathrm{NiO}$ crystallites within SBA-15 after impregnation, drying and calcination.

crystallites in combination with the observed loss in pore volume suggests that the $\mathrm{NiO}$ phase was located inside the SBA-15 pores.

Characterization by ET. TEM observations, as in Figure $4 \mathrm{a}$, confirm that the $\mathrm{NiO}$ phase was assembled inside the SBA15 pores. Using ET, the actual 3D structure is resolved. Figure $4 \mathrm{~b}$ shows a $0.54 \mathrm{~nm}$ thick numerical cross section through the reconstruction of the support particle A. It is immediately apparent that not all pores of the support contained $\mathrm{NiO}$ crystallites. In this particular structure, approximately $45 \%$ of the pores were filled. This phenomenon, of filling only a fraction 


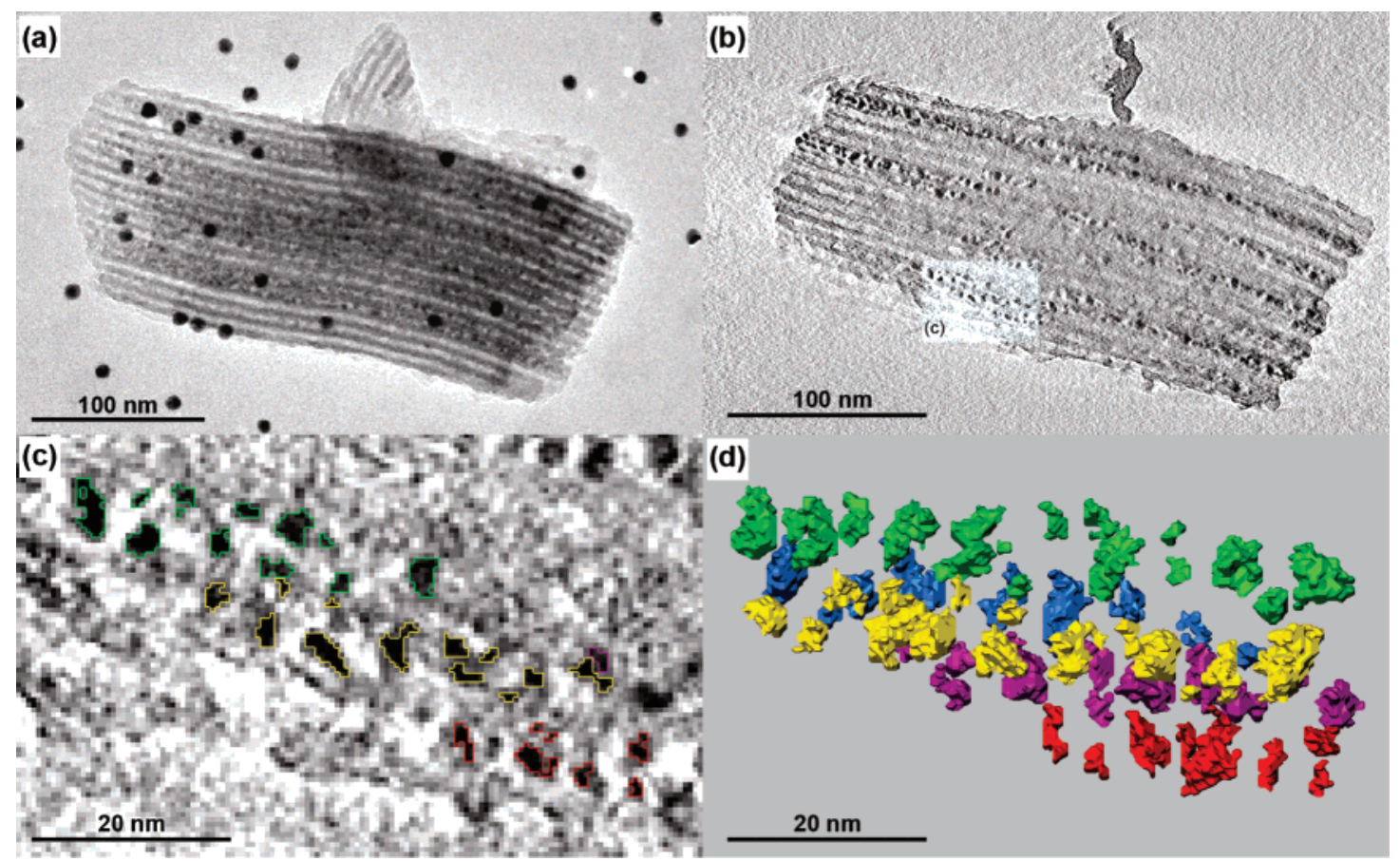

Figure 4. TEM image of NiO/SBA-15 structure designated particle A. The dark spots are $10 \mathrm{~nm}$ gold particles used for alignment of the tilt series (a). Also shown is a $0.54 \mathrm{~nm}$ thick numerical cross section through the same object (b), with the magnified part of the cross section with a colored outline of the segmented $\mathrm{NiO}$ crystals. Different colors have been assigned to crystals in different pores (c). Additionally shown is a surface view of segmented NiO particles (d).

of the pores, has previously been reported for $\mathrm{ZrO}_{2} / \mathrm{SBA}-15^{8}$ and $\mathrm{MnO}_{x} / \mathrm{SBA}-15^{41}$ and might be related to an inhomogeneous concentration of surface hydroxyl groups. ${ }^{42,43}$ The extent of pore filling by $\mathrm{NiO}$ throughout the whole SBA- 15 structure can be best observed by consulting the supporting movie slices.mpg.

For a quantitative characterization, image segmentation was applied. In Figure 4c, a part of the numerical cross section has been magnified. The manually traced contours of the $\mathrm{NiO}$ are marked in different colors. Crystallites belonging to different pores have been color coded green, blue, yellow, pink, and red. A 3D surface model of the $\mathrm{NiO}$ is displayed in Figure 4d. This example shows how ET in combination with a posteriori image processing provides the volume and the $3 \mathrm{D}$ location of the $\mathrm{NiO}$ crystallites in individual SBA-15 pores. For further analysis a total of $299 \mathrm{NiO}$ crystallites, contained in six filled pores (three in support particles A and B), were segmented. The six filled pores were chosen from different regions of the two SBA-15 structures to ensure proper statistical sampling. The relative location of the three pores in support particle A is indicated in the supporting movie slices.mpg.

For accurate volume measurements reconstruction artifacts have to be considered. Dense objects will appear elongated in the tomographic reconstruction, an effect which is known as the missing wedge problem. ${ }^{44-46}$ The missing wedge of information in Fourier space is caused by the inherent limit to

(41) Imperor-Clerc, M.; Bazin, D.; Appay, M.-D.; Beaunier, P.; Davidson, A Chem. Mater. 2004, 16, 1813 .

(42) Moreno, M. S.; Weyland, M.; Midgley, P. A.; Bengoa, J. F.; Cagnoli, M. V.; Gallegos, N. G.; Alvarez, A. M.; Marchetti, S. G. Micron 2006, 37, 52.

(43) Jentys, A.; Kleestorfer, K.; Vinek, H. Microporous and Mesoporous Mater 1999, 27,321

(44) Penczek, P.; Marko, M.; Buttle, K.; Frank, J. Ultramicroscopy 1995, 60 , 393.

(45) Mastronarde, D. N. J. Struct. Biol. 1997, 120, 343.

(46) Midgley, P. A.; Weyland, M. Ultramicroscopy 2003, 96, 413. the range of tilt angles, e.g., the finite thickness of the specimen holder and restrictions of the microscope stage. ${ }^{44-46}$ The elongation factor, $e$, which occurs in the direction of the electron beam, can be calculated from the maximum tilt angle $(\alpha)^{: 47}$

$$
e=\sqrt{\frac{\alpha+\sin \alpha \cos \alpha}{\alpha-\sin \alpha \cos \alpha}}
$$

Measured volumes of the $\mathrm{NiO}$ crystals have to be corrected for elongation by dividing by the elongation factor. Simple division can be applied, since elongation only occurs along one axis of the three-dimensional structure.

A statistical analysis of the $299 \mathrm{NiO}$ crystallite volumes (Figure 5a) showed that a large number of small NiO crystallites $\left(<30 \mathrm{~nm}^{3}\right)$ were present. The measured volumes are, in contrast to those resulting from techniques like TEM or XRD, not based on a sphere model. The volume statistics could be fitted well to a log-normal distribution as predicted by Granqvist to be observed independently of the prevalent growth mechanism. ${ }^{48,49}$

For comparison with XRD, the size of each $\mathrm{NiO}$ crystallite can be estimated by its equivalent diameter, i.e., the diameter of a sphere having the same volume. The resulting size distribution and log-normal fit are given in Figure 5b. Despite the fact that the crystallites did not appear to be spherical, a close match is observed. When volume weighting was applied to the log-normal fit, the curve maximum shifted from 3 to 4 $\mathrm{nm}$, which corresponds very well with the $\mathrm{NiO}$ crystallite diameter obtained by XRD. The deviation at a diameter value of $5 \mathrm{~nm}$ was caused by poor statistical sampling as seen in the

(47) Radermacher, M.; Hoppe, W. Proceedings of the Seventh European Congress on Electron Microscopy, Den Haag, The Netherlands; Institute of Physics: London, 1980; p 132.

(48) Granqvist, C. G.; Buhrman, R. A. J. Catal. 1976, 42, 477.

(49) Datye, A. K.; Xu, Q.; Kharas, K. C.; McCarty, J. M. Catal. Today 2006, 111,59 . 
(a)

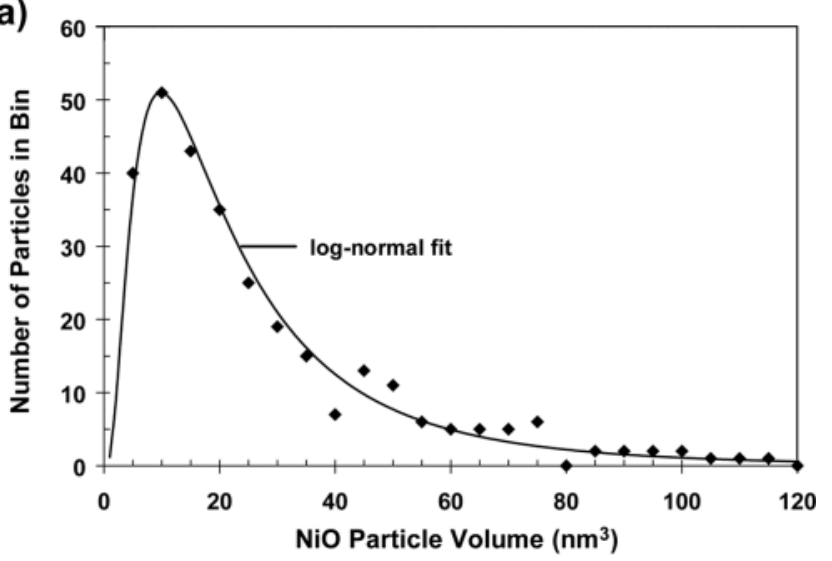

(b)

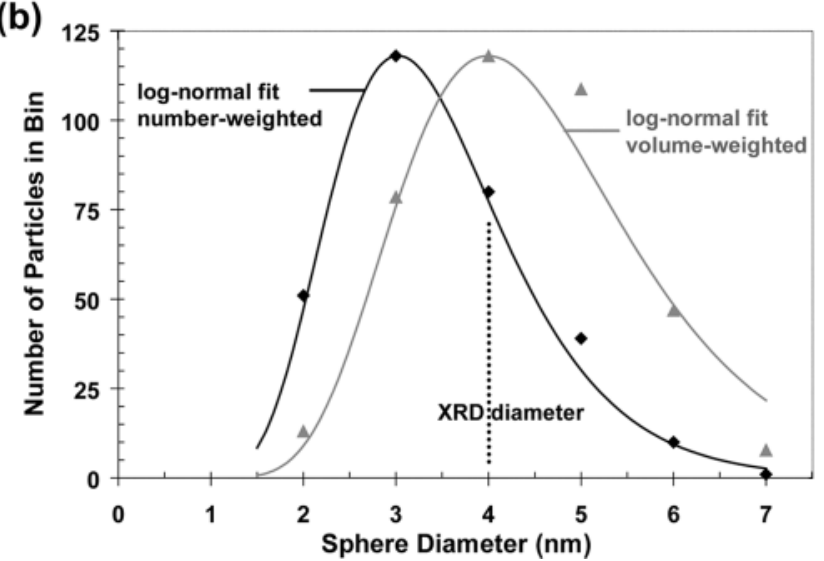

Figure 5. Volume statistics over $299 \mathrm{NiO}$ particles (a) and size distributions of $\mathrm{NiO}$ particles expressed in diameter of sphere having the same volume (b).

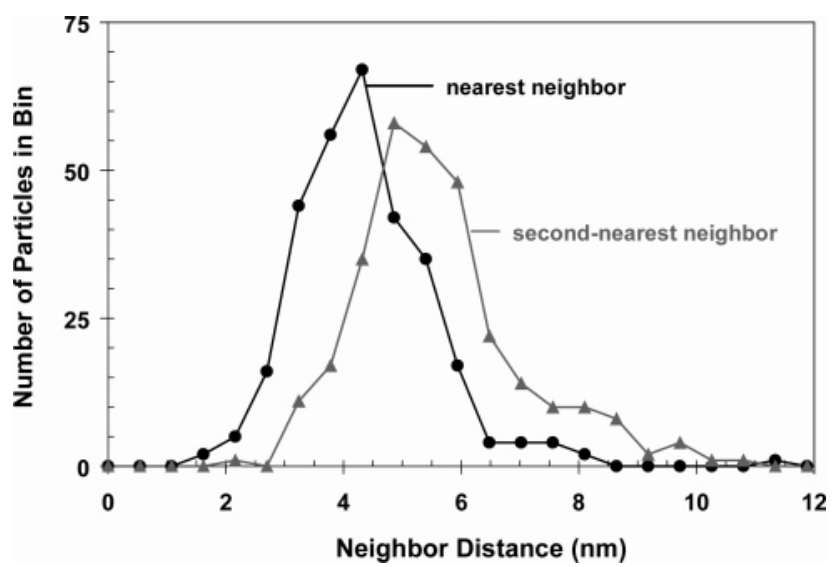

Figure 6. Statistical analysis of the 3D nearest- and 3D second-nearestneighbor distances from $299 \mathrm{NiO}$ crystallites.

region between 60 and $80 \mathrm{~nm}^{3}$ in Figure 5a. The observation that particles of $6 \mathrm{~nm}$ and above were rare was also supported by the $\mathrm{N}_{2}$-physisorption measurements and the inferred absence of mesopore blocking.

In addition to the volume, the locations of all $299 \mathrm{NiO}$ crystallites were determined from their centers-of-mass. The results of a statistical analysis of the nearest- and second-nearestneighbor distances between $\mathrm{NiO}$ crystallites can be seen in Figure 6. Distances were measured in 3D between the centersof-mass of adjacent $\mathrm{NiO}$ crystallites belonging to the same pore. Both curves are narrow indicating a homogeneous distribution
Table 1. Properties of NiO-Filled SBA-15 Pores Derived from the Reconstructions of Particles A and B

\begin{tabular}{ccccc}
\hline pore & length $(\mathrm{nm})$ & $\mathrm{NiO}$ vol $\left(\mathrm{nm}^{3}\right)$ & $\mathrm{SiO}_{2}$ vol $\left(\mathrm{nm}^{3}\right)$ & NiO loading $(\mathrm{wt} \%)$ \\
\hline $\mathrm{A} 1$ & 134 & 1650 & 5588 & 47 \\
$\mathrm{~A} 2$ & 211 & 1998 & 8799 & 41 \\
$\mathrm{~A} 3$ & 198 & 1711 & 8257 & 39 \\
$\mathrm{~B} 1$ & 94 & 939 & 3920 & 42 \\
$\mathrm{~B} 2$ & 111 & 1081 & 4629 & 42 \\
$\mathrm{~B} 3$ & 139 & 916 & 5797 & 32 \\
all & 887 & 8295 & 36991 & 41 \\
\hline
\end{tabular}

and very few isolated crystallites. In conjunction with the measured particle size distribution, neighbors were separated by only $1-3 \mathrm{~nm}$. To our knowledge, no other technique can provide this local nanoscale information.

Nanoscale Loading Model. The loading of an individual SBA-15 pore can be calculated if the $\mathrm{NiO}$ and the $\mathrm{SiO}_{2}$ volumes associated with that particular pore are known. The $\mathrm{NiO}$ volume/ filled pore equals the sum over the individual crystallite volumes, while the $\mathrm{SiO}_{2}$ volume can be calculated from a geometrical model:

$$
V_{\mathrm{SiO}_{2}}=\frac{\frac{\sqrt{3}}{2} a_{0}^{2}}{1+\rho_{\mathrm{SiO}_{2}}\left(V_{\text {pores }}+V_{\mathrm{NiO}}\right)} \cdot L_{\text {pore }}
$$

with $a_{0}=10.5 \mathrm{~nm}$ the unit cell size, $\rho_{\mathrm{SiO}_{2}}=2.2 \mathrm{~g} \cdot \mathrm{cm}^{-3}$ the density of silica, $V_{\text {pores }}=0.54 \mathrm{~cm}^{3} \cdot \mathrm{g}^{-1}$ the pore volume measured by $\mathrm{N}_{2}$-physisorption, $V_{\mathrm{NiO}}=0.047 \mathrm{~cm}^{3} \cdot \mathrm{g}^{-1}$ the volume of impregnated $\mathrm{NiO} / \mathrm{g}$ of silica, and $L_{\text {pore }}$ in $\mathrm{nm}$ the pore length. The pore length is approximated by the center-of-massdistance between the first and the last segmented particle in the pore.

Detailed values for occupied pore length, segmented $\mathrm{NiO}$ volume, calculated $\mathrm{SiO}_{2}$ volume, and the resulting loading in individual pores are given in Table 1 . To our surprise a local loading much higher than the applied $24 \mathrm{wt} \%$ was found. The loading average of $41 \mathrm{wt} \%$ corresponds to a $\mathrm{NiO}$ content in the examined pores that is more than twice the expected value. This observation is in line with the large percentage of unfilled pores that arguably compensate for the high local loading.

Variations along the pores were studied by calculating the loading in 10 consecutive pore segments as displayed for pore A3 in Figure 7. Information on crystallite volume vs position and a surface view complement the results. In general a homogeneous distribution of the number of $\mathrm{NiO}$ particles is seen, leading to few isolated crystallites as derived from the nearestneighbor distances. A preference toward higher loading at the pore mouth was not found. Although small and large particles were mostly distributed at random, the local loading decreased in regions with mainly small particles.

Any conclusions to be drawn from this nanoscale pore loading model have to be seen with regard to its limitations. Limiting factors are the pore length approximation, the segmentation accuracy, and the fact that $\mathrm{NiO}$ particles below $3 \mathrm{~nm}^{3}(\sim 1.8$ $\mathrm{nm}$ sphere diameter) have not been detected. A $10 \%$ error in both $\mathrm{NiO}$ and $\mathrm{SiO}_{2}$ volumes translated into 5 wt \% difference in local loading. Effects of the reconstruction point-spread function beyond the elongation factor were not considered and might further decrease the segmentation accuracy and, consequently, the size determination. 
(a)

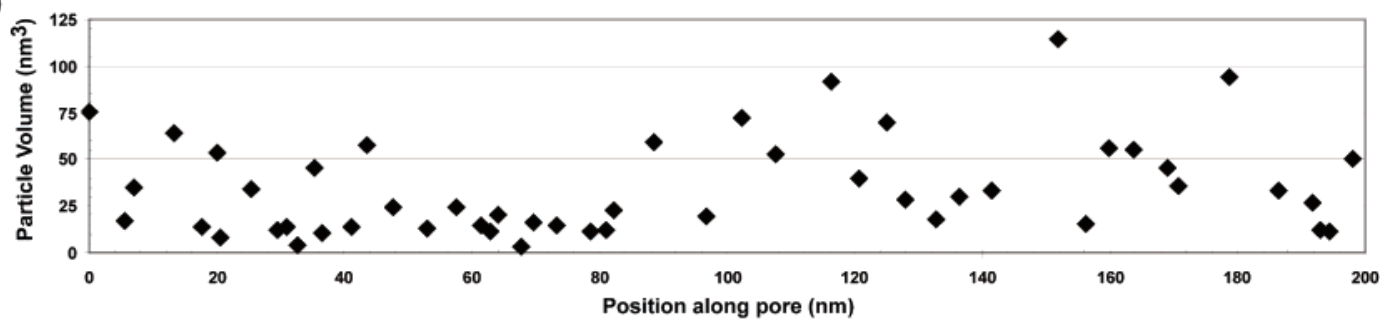

(b)

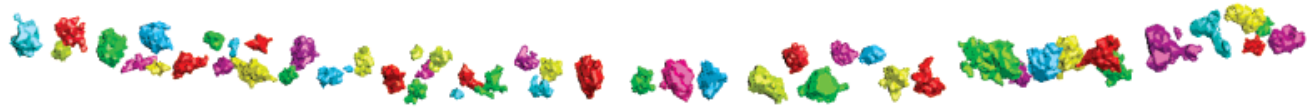

(c)

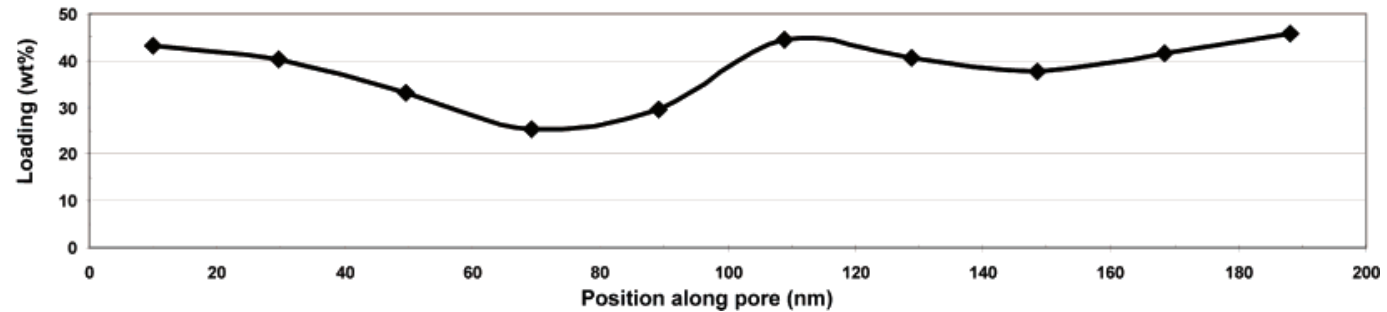

Figure 7. Properties of pore $\mathrm{A} 3$ of NiO/SBA-15: position and corresponding volume of individual $\mathrm{NiO}$ crystallites (a); surface view of $\mathrm{NiO}$ crystallites (b); local $\mathrm{NiO}$ loading calculated for 10 successive segments of the SBA-15 pore (c).

Electron tomograms contain large amounts of potentially quantitative information, but the problem remains of how to extract it. Manual segmentation, although subjective and its error undetermined, is one rather straightforward solution to the problem. On the basis of a total of 299 examined $\mathrm{NiO}$ crystallites, a sufficient statistical sampling was given. Volume and particle size distributions corresponded well with numerical fits of a commonly assumed log-normal distribution. ${ }^{49}$ The close match of the ET derived particle size to XRD results strongly suggests that the studied crystallites were representative for the bulk.

\section{Conclusions}

ET in combination with a posteriori image processing was successfully applied to study the size distribution and $3 \mathrm{D}$ location of single $\mathrm{NiO}$ crystallites in individual SBA-15 pores. Statistical analysis confirms a commonly assumed log-normal size distribution with a volume-weighted maximum at $4 \mathrm{~nm}$, which was in excellent agreement with the crystallite size determined by XRD. Interparticle distances between nearestneighboring crystallites were $1-3 \mathrm{~nm}$ with very few isolated crystallites. The local loading in filled pores was almost twice the applied overall loading of the support, and significant variations existed between and along the pores. The high local loading was compensated by a large percentage of unfilled pores. This suggests that a very high local loading combined with a high dispersion is achievable, if the filling of the pores during impregnation and drying is improved. ET has provided new quantitative information on the $3 \mathrm{D}$ structure of NiO/SBA-15 and is expected to play a major role in the characterization of nanostructured materials, in general, and heterogeneous catalysts, in particular.

Acknowledgment. H.F. and K.P.d.J. acknowledge support by the National Research School Combination Catalysis. Microscopy was performed at the Electron Microscopy Group Utrecht (EMU). We thank A. J. Koster, W. J. C. Geerts, J. D. Meeldijk, T. P. van der Krift, M. N. Lebbink, A. Yakushevska, and M. Barcena for their support.

Supporting Information Available: Slices.mpg, a movie of consecutive numerical cross sections through reconstruction $\mathrm{A}$ of $\mathrm{NiO} / \mathrm{SBA}-15$ structure, with the relative location of the three segmented SBA-15 pores indicated. This material is available free of charge via the Internet at http://pubs.acs.org.

JA0728876 